http://jmscr.igmpublication.org/home/ ISSN (e)-2347-176x ISSN (p) 2455-0450 crossref DOI: https://dx.doi.org/10.18535/jmscr/v7i9.09

\title{
Estimation of Placental Thickness by Ultrasonography and its Correlation with Gestational Age in Normal and Intrauterine Growth Retardation Pregnancies in Late $2^{\text {nd }}$ And $3^{\text {rd }}$ Trimester
}

\author{
Authors \\ Dr Ashok Kumar Verma ${ }^{1}$, Dr Krishna Raj ${ }^{2}$, Dr Rajlaxmi Yadav ${ }^{3}$, Dr Saurabh Pandey \\ ${ }^{1}$ Assistant Professor, Department of Radiodiagnosis, GSVM Medical College, Kanpur, UP, India \\ 2,3,4 Junior Resident, Department of Radiodiagnosis, GSVM Medical College, Kanpur, UP, India
}

\begin{abstract}
Introduction: USG is modality of choice for fetal evaluation, estimation of gestational age and detection of IUGR pregnancies.

Aim: The study was conducted with the aim of evaluating placental thickness, measured at the level of insertion of umbilical cord and its role in estimation of gestational age of the fetus and in predicting normal and IUGR fetal outcome.

Material and Methods: Using Ultrasonography placental thickness was measured at cord insertion site from $18^{\text {th }}$ to $40^{\text {th }}$ gestational age by LMP in pregnant woman. At term cases were categorized as normal and IUGR on the basis of fetal weight. Correlation of placental thickness with gestational age was calculated and compared in both group to find any statistically significant difference.

Result: A positive correlation was observed between placental thickness and gestational age in both groups. Pearson's correlation coefficient (r) was calculated for both groups and more strength of correlation was found in normal group. Value of ' $r$ ' is 0.3221 and 0.7450 in IUGR and normal cases respectively. In normal cases placental thickness in mm corresponds to gestational age in weeks up to 32 weeks. After that mean placental thickness remains nearly stationary up to 40 weeks with average thickness $31 \mathrm{~mm}$. In $18^{\text {th }} 19^{\text {th }}$ and $26^{\text {th }}$ weeks placental thickness is more in IUGR group $(22.5 \pm 4.2$, $28.1 \pm 5.2$ and $31 \pm 5.5)$ as compared to normal group $(18.7 \pm 1.6,19.6 \pm 1.9$ and 26 \pm 3.1$)$. So, increased placental thickness in these gestational weeks can suggest abnormal fetal outcome.

Conclusion: Placental thickness at the umbilical cord insertion site can be used as an accurate sonographic parameter in the assessment of gestational age in singleton normal pregnancies because of its strong positive linear correlation with gestational age.
\end{abstract}

\section{Introduction}

USG has an important role in detection of intrauterine growth restriction (IUGR) pregnancies. IUGR is a common diagnosis in obstetrics and carries an increased risk of perinatal mortality and morbidity. Identification of IUGR is crucial because proper evaluation and management can result in a favorable outcome. The placenta is a fetal organ which provides the physiologic link between a pregnant woman and the fetus.The placenta performs respiratory, excretory, nutritional, and endocrine functions for the fetus. It transfers gases, such as oxygen and carbon dioxide, waste products such as urea, 
nutrients such as glucose and hormones between the maternal and fetal circulation. The placenta develops from the chorionic villi at the implantation site at about the fifth week of gestation and by the ninth or tenth week, the diffuse granular echo texture of the placenta is clearly apparent at sonography Ultrasound biometry is the gold standard for assessment of fetal size and identification of IUGR. The placenta is a fetal organ of pregnancy, responsible for providing nutrition and oxygen to the fetus as well as excretory functions. Ultrasound is the first-line modality in imaging the placenta due to its wide availability and its use of non-ionizing radiation. Donald ${ }^{[1]}$ introduced placental localization by ultrasound in 1965. Studies have shown that diminished placental size precedes fetal growth retardation as IUGR is associated with impoverished villous development and fetoplacental angiogenesis. Beside that large placenta may indicate an infection, anemia or Triploid. Thickened placentas, suggest Primary maternal Cytomegalovirus infection and fetal disease. Increased mortality rate related to fetal anomalies and higher rates of both small for gestational age, and large, for gestational age infants at term also related to Thickened placentas. Growth retardation is associated with Placental thickness of less than $2.5 \mathrm{~cm}$. while Diabetes Mellitus, fetal hydrops and intrauterine fetal infections is associated with thick placentas.

Placental thickness also can be used as a gestational age indicator due to a linear increase in its thickness with advancing gestational age as reported in the previous studies by Mital et $a l .{ }^{[2]}$ and Jain et al. ${ }^{[3]}$

The purpose of the present study is measuring placental thickness at the level of umbilical cord insertion in women who are sure of their last menstrual period (LMP) to assess the relationship of placental thickness with gestational age by LMP and to compare this correlation in normal and IUGR pregnancies to find whether any significant difference is present between these groups.

\section{Material and Methods}

This was a prospective cross sectional study conducted in the department of Radiodiagnosis in collaboration with the department of Obstetrics and gynecology, G.S.V.M. Medical College, Kanpur within one year duration of 2016-2017. All pregnant women who were sure of LMP coming for antenatal USG from 18th to 40th gestational weeks were included in the study.Women with diabetes mellitus, multiple pregnancies, polyhydromnios, diagnosed cases of fetal hydrops and pregnancies with any morphological variation in placenta and cord insertion site were excluded from the study. Women with poor visualization of cord insertion site also were excluded. USG was performed using a SONOACE X8 system with $2-5 \mathrm{MHz}$ convex array transducer. Placental thickness at cord insertion site was measured keeping the plane of transducer perpendicular to placental basal and chorionic plates (Figure 1). Other variables like maternal age, number of pregnancy, previous obstetric history, BMI, placental position, hemoglobin \%, blood pressure etc were recorded. .Cases were categorised into two groups based on outcome fetal weight at term.

Group A (IUGR): Outcome fetal weight < 2500gm

Group B (Normal): Outcome fetal weight > 2500gm

Statistical Methods: The mean values of placental thickness, in $\mathrm{mm}$, along with respective standard deviation (SD) were computed for each gestational age by LMP in both groups. The correlation and regression analysis has been carried out to quantify the relationship between the gestational age in weeks and placental thickness in $\mathrm{mm}$ in both groups. A 'p' value $<0.05$ was considered significant. Unpaired ' $t$ '-test was applied to compare the difference between the means of the two groups for each gestational age by LMP.

The study protocol was approved by the ethical committee of GSVM medical college, Kanpur. 


\section{Results}

Ultrasonographic examination was conducted of 627 pregnant women who were sure of LMP. 182 women were lost to follow up. Remaining 445 participants were followed till delivery for fetal outcome and comparative and correlative study was conducted to see relation between placental thickness and gestational age by LMP in both group.

On follow up out of 445 cases, 147 cases were included in group A and 298 cases in group B.

Maternal age distribution: Maximum cases observed in age group 21-25 years. (Figure: 1)

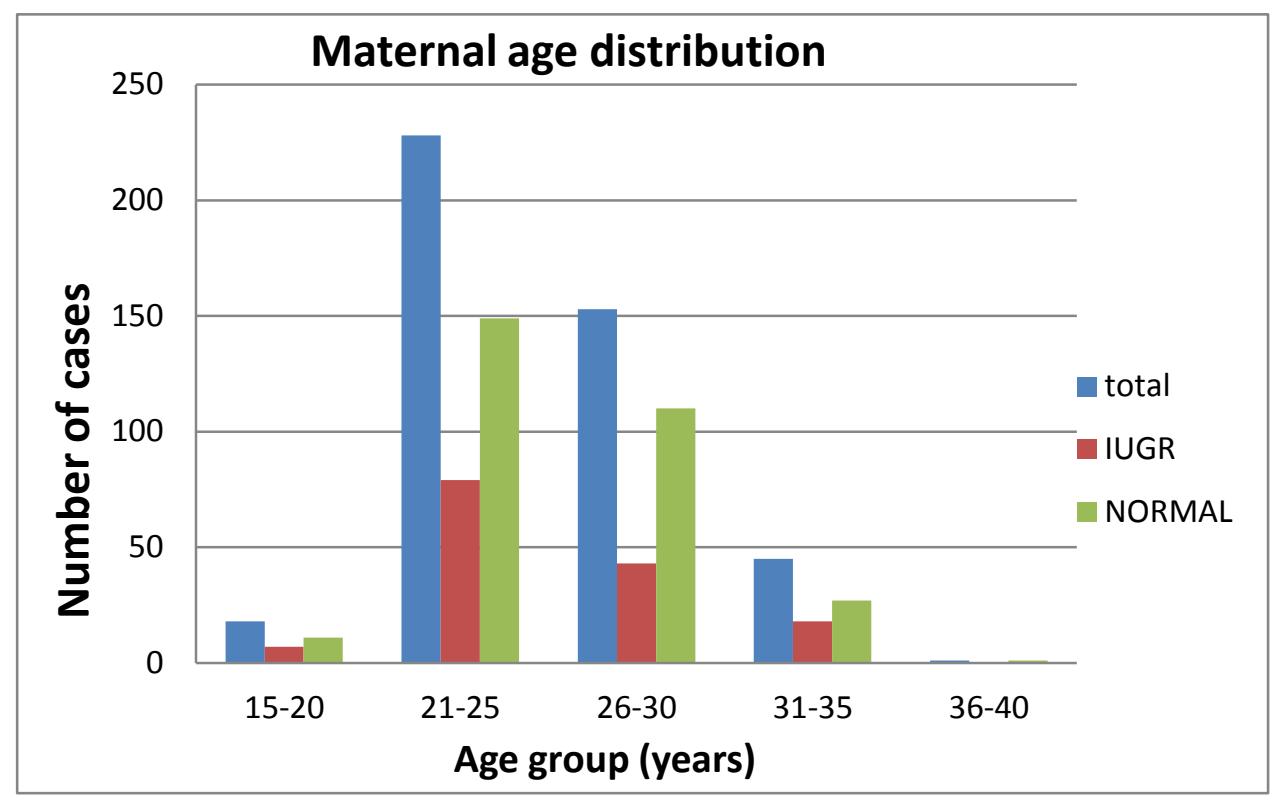

Figure: 1 : Maternal age distribution

Placental position distribution: (Figure: 2)

\section{placental position in total pregnancies}

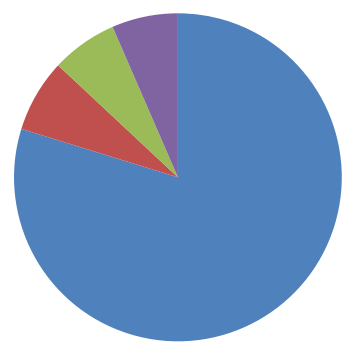

$$
\begin{aligned}
& \text { Anterior } 79 \% \\
& \text { posterior } 7 \% \\
& \text { lateral } 6.5 \% \\
& \text { fundal } 6.5 \%
\end{aligned}
$$

Figure: 2: Distribution of placental position

The number of measurements for each week of gestational age (LMP):

Total 445 measurements were taken. Minimum number of measurement was 1 and 4 and maximum number was 15 and 28 in IUGR and normal cases respectively. (Figure: 3 ) 


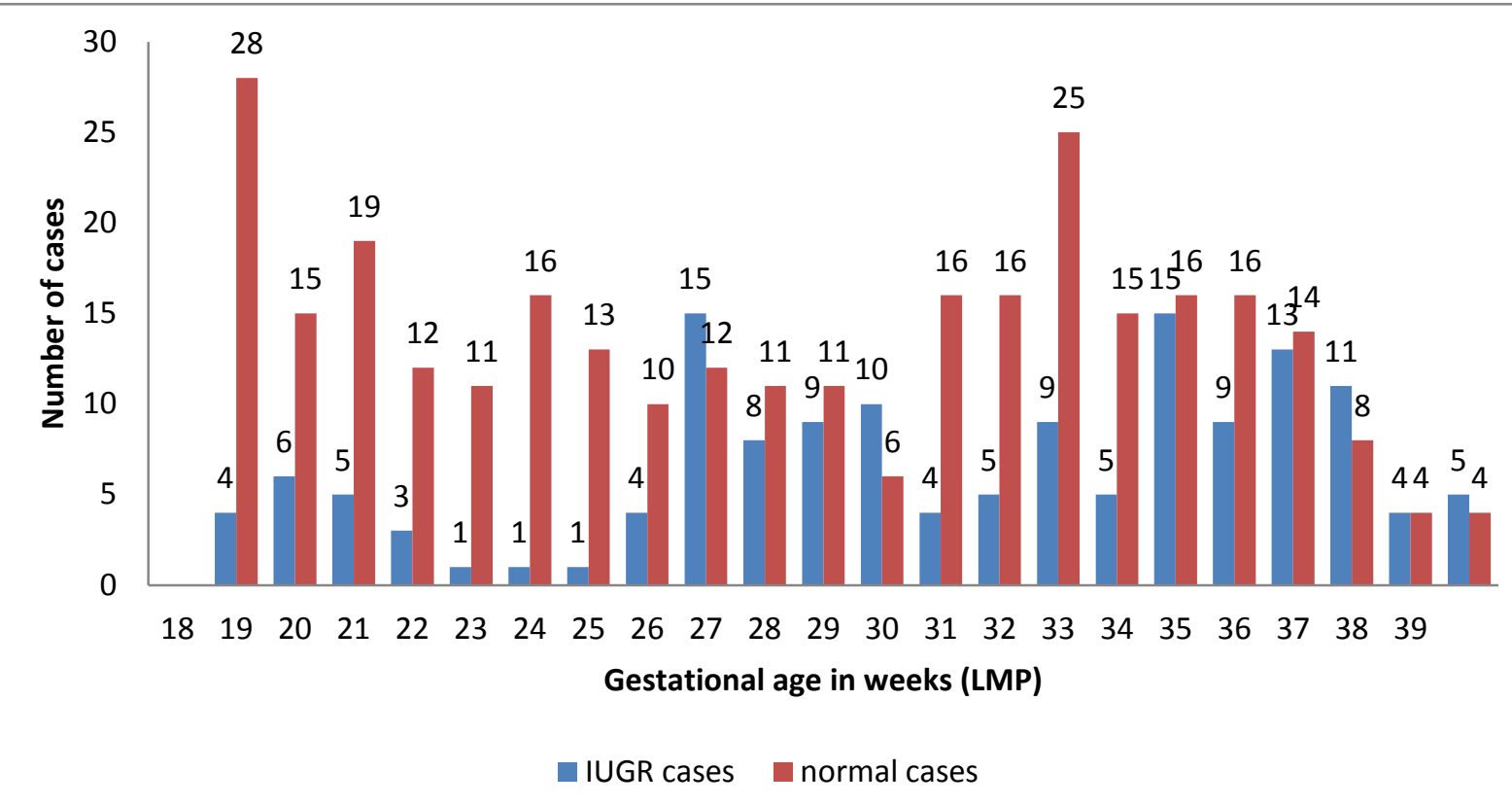

Figure: 3: The number of measurements for each week of gestational age (LMP) in IUGR and Normal cases.

Relationship between gestational age (LMP) and placental thickness in both groups:

Mean value along with respective standard deviation of placental thickness was calculated for each gestational week in both IUGR and normal groups as shown in table 3. Unpaired student ' $t$ 'test was applied to find any significant difference in both groups. $p$ value are also shown in table: 1

Table 1 : Relationship between gestational age (LMP) and placental thickness in both groups.

\begin{tabular}{|c|c|c|c|c|c|c|c|c|c|}
\hline \multirow[t]{2}{*}{$\begin{array}{l}\text { GA by } \\
\text { LMP }\end{array}$} & \multirow[t]{2}{*}{$\begin{array}{l}\text { Total } \\
\text { no.ofcases }\end{array}$} & \multicolumn{3}{|c|}{ IUGR } & \multicolumn{3}{|c|}{ NORMAL } & \multirow[t]{2}{*}{$\mathrm{p}$ value } & \multirow[t]{2}{*}{ Inference } \\
\hline & & MEAN & SD & $\begin{array}{l}\text { No. of } \\
\text { cases }\end{array}$ & MEAN & SD & $\begin{array}{l}\text { No. of } \\
\text { cases }\end{array}$ & & \\
\hline $18-18.6$ & 32 & 22.5 & 4.2 & 4 & 18.7 & 1.6 & 28 & $<0.05$ & Sig \\
\hline $19-19.6$ & 21 & 28.1 & 5.2 & 6 & 19.6 & 1.9 & 15 & $<0.05$ & Sig. \\
\hline $20-20.6$ & 24 & 23.4 & 5.2 & 5 & 20.6 & 2.8 & 19 & $>0.05$ & non sig \\
\hline $21-21.6$ & 15 & 22 & 1 & 3 & 21.6 & 2.7 & 12 & $>0.05$ & non.sig \\
\hline $22-22.6$ & 12 & 25 & 0 & 1 & 23.1 & 6.1 & 11 & & - \\
\hline $23-23.6$ & 17 & 29 & 0 & 1 & 23.8 & 2.6 & 16 & & - \\
\hline $24-24.6$ & 14 & 27 & 0 & 1 & 25 & 1.9 & 13 & & - \\
\hline $25-25.6$ & 14 & 27 & 4.8 & 4 & 25.5 & 3 & 10 & $>0.05$ & non.sig \\
\hline $26-26.6$ & 27 & 31 & 5.5 & 15 & 26 & 3.1 & 12 & $<0.05$ & Sig \\
\hline $27-27.6$ & 19 & 30.2 & 5.2 & 8 & 27 & 2.1 & 11 & $>0.05$ & non.sig \\
\hline $28-28.6$ & 20 & 28.5 & 4 & 9 & 28.1 & 3.3 & 11 & $>0.05$ & non.sig \\
\hline $29-29.6$ & 16 & 31 & 5.3 & 10 & 28.5 & 2.5 & 6 & $>0.05$ & non.sig \\
\hline $30-30.6$ & 20 & 28.2 & 3.8 & 4 & 29.1 & 2.7 & 16 & $>0.05$ & non.sig \\
\hline $31-31.6$ & 21 & 27.4 & 5.4 & 5 & 30.7 & 3.3 & 16 & $>0.05$ & non.sig \\
\hline $32-32.6$ & 34 & 30.4 & 9.7 & 9 & 32 & 5.4 & 25 & $>0.05$ & non.sig \\
\hline $33-33.6$ & 20 & 28.3 & 3.9 & 5 & 30.9 & 5.8 & 15 & $>0.05$ & non.sig \\
\hline $34-34.6$ & 31 & 34.1 & 8.5 & 15 & 31.8 & 2.9 & 16 & $>0.05$ & non.sig \\
\hline $35-35.6$ & 25 & 30.6 & 7.5 & 9 & 31.2 & 4.8 & 16 & $>0.05$ & non.sig \\
\hline $36-36.6$ & 27 & 32.4 & 7.2 & 13 & 33 & 5.1 & 14 & $>0.05$ & non.sig \\
\hline $37-37.6$ & 19 & 33.6 & 8.5 & 11 & 29.8 & 5 & 8 & $>0.05$ & non.sig \\
\hline $38-38.6$ & 8 & 33 & 9.2 & 4 & 31.5 & 3.7 & 4 & $>0.05$ & non.sig \\
\hline $39-40$ & 9 & 28.8 & 6.7 & 5 & 30.5 & 7 & 4 & $>0.05$ & non.sig \\
\hline Total & 445 & & & 147 & & & 298 & & \\
\hline
\end{tabular}


A positive correlation was observed between placental thickness and gestational age by LMP in both groups. Pearson's correlation coefficient (r) was calculated for both groups and more strength of correlation was found in normal group. Value of ' $r$ ' is 0.3221 and 0.7450 in IUGR and normal cases respectively.

In figure: 4 a line diagram showing mean placental thickness in different gestational age (LMP) shows linear relation in both groups. In normal cases placental thickness in $\mathrm{mm}$ corresponds to gestational age in weeks up to 32 weeks. After that mean placental thickness remains nearly stationary upto 40 weeks with average thickness $31 \mathrm{~mm}$.

In IUGR group placental thickness in $\mathrm{mm}$ corresponds with gestational age in 21, 28 and 34 weeks. In rest of gestational period placental thickness mean in $\mathrm{mm}$ is higher than gestational age in week up to $29^{\text {th }}$ gestational week after that mean value is lower than gestational week till $40^{\text {th }}$ week.

Regression analysis yielded linear equation of relationship in both groups with gestational age by LMP (Y) and placental thickness (X) as follows:

IUGR- $\quad Y=22.1068+0.2692 X$

Normal- $\quad \mathrm{Y}=6.062+0.7947 \mathrm{X}$

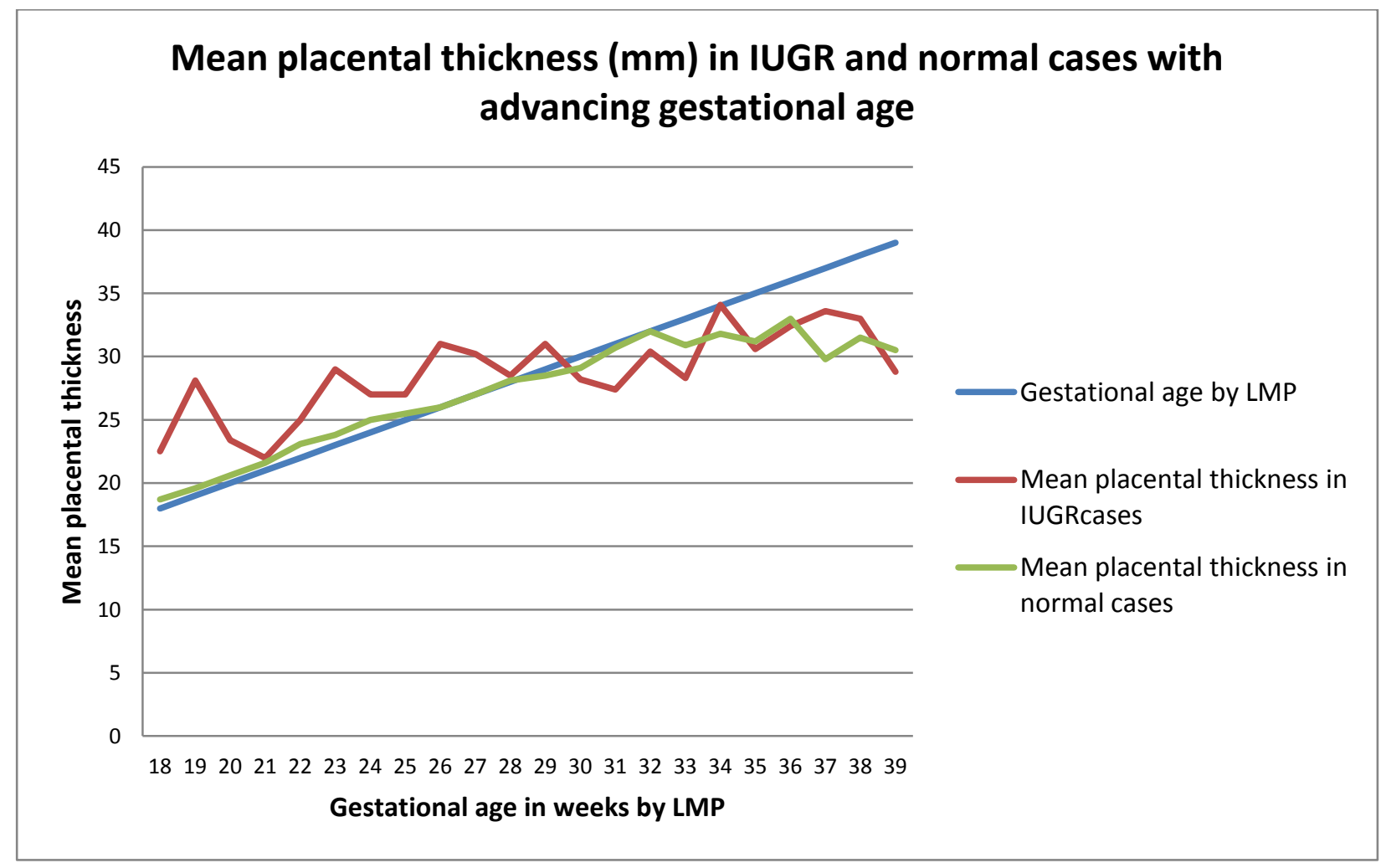

Figure: 4: Line diagram between placental thickness mean (mm) and gestational age (LMP) in both groups

Distribution of placental thickness in both groups in different gestational weeks:

In normal cases minimal placental thickness measured was 16 in 18 th gestational week and maximum thickness measured was 44 in $36^{\text {th }}$ gestational week.

In IUGR cases minimal placental thickness measured was 17 and maximum thickness measured was 49 in $36^{\text {th }}$ gestational week.
It is seen that standard deviation is more in IUGR cases in most of gestational weeks i.e data are more widely spread around mean in IUGR cases as compared to normal cases. Distribution of placental thickness of each case in both groups are shown in figure: 5 . 


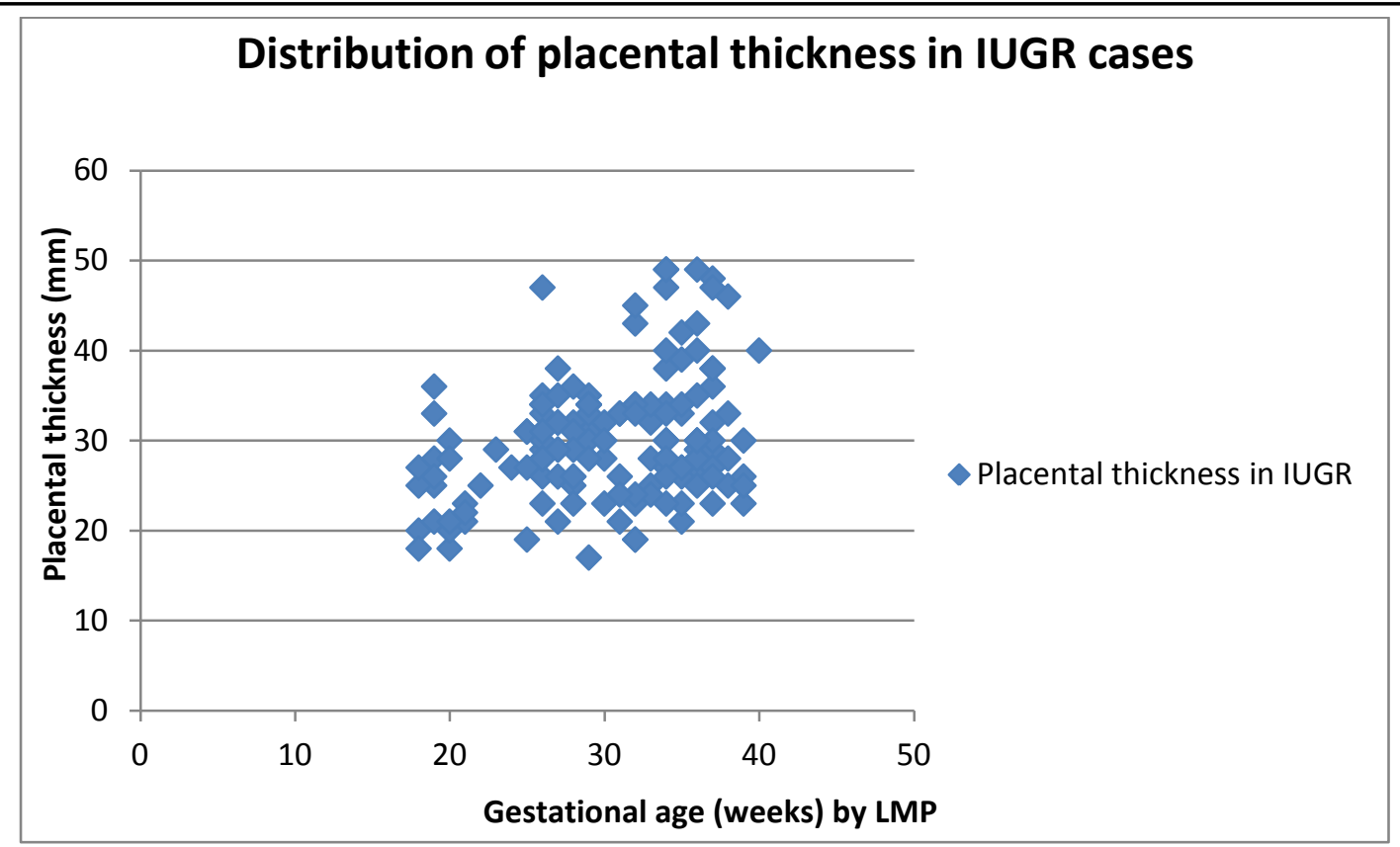

(a)-IUGR

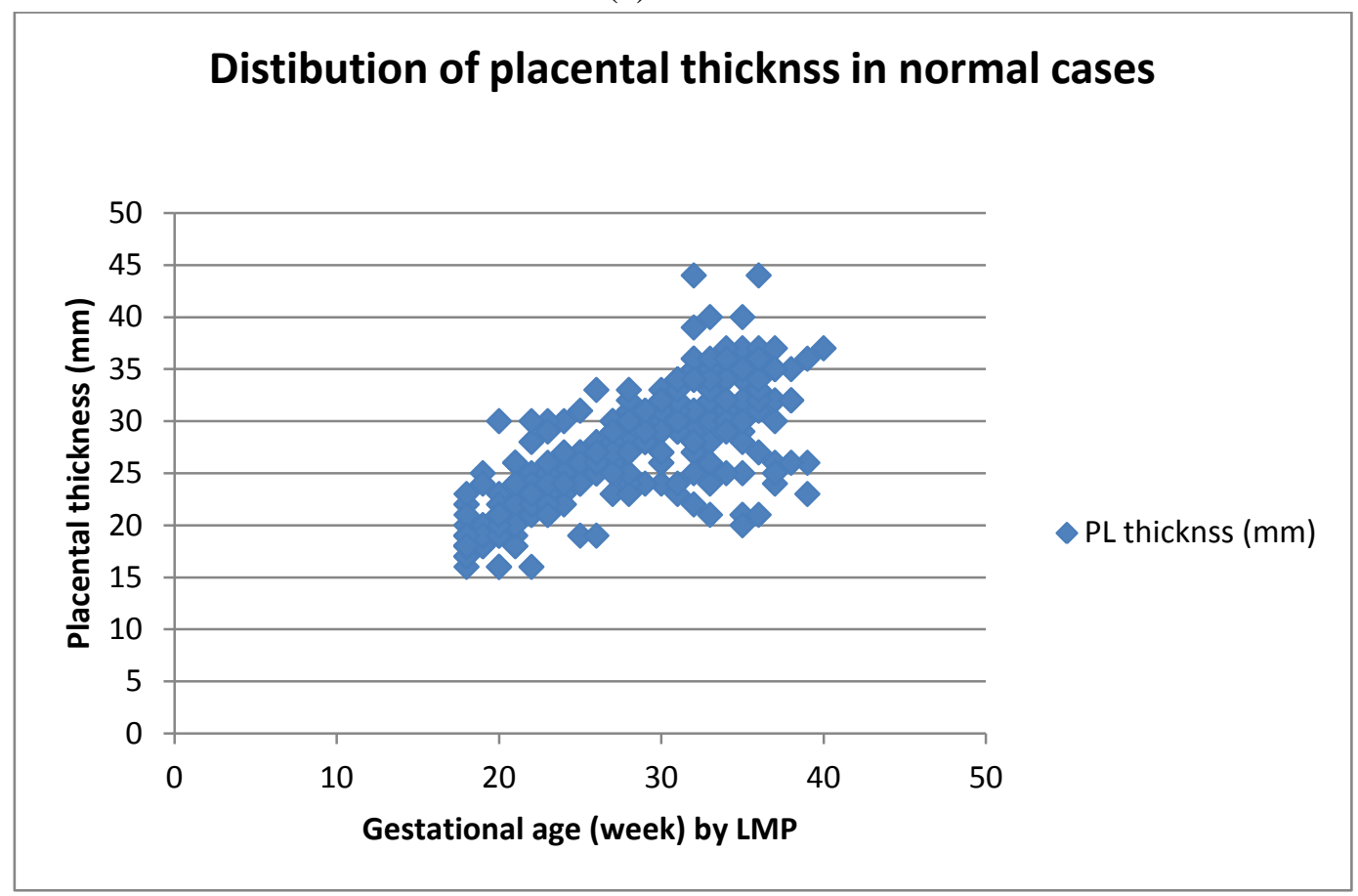

(b)-Normal

Figure: 5: Distribution of placental thickness in each group in different gestational weeks by LMP.

Comparison of placental thickness in normal and IUGR groups

Using unpaired group mean test (student ' $\mathrm{t}$ ' test), we found that there is significant difference in placental thickness seen in $18^{\text {th }}, 19^{\text {th }}$ and $26^{\text {th }}$ gestational weeks by LMP (with 'p' value $<0.05$ ). There is statistical non-significant difference seen in rest of gestational week between IUGR and normal groups (with 'p' value $>0.05$ ).
In $18^{\text {th }} 19^{\text {th }}$ and $26^{\text {th }}$ weeks placental thickness is more in IUGR group $(22.5 \pm 4.2,28.1 \pm 5.2$ and $31 \pm 5.5)$ as compared to normal group $(18.7 \pm 1.6$,

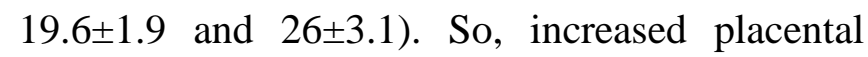
thickness in these gestational weeks can suggest abnormal fetal outcome.

\section{Distribution of hemoglobin concentration:}

In the total 445 study participants range of hemoglobin distribution was $4.3 \%$ to $12.7 \%$. 
Hemoglobin range of $9-10 \%$ is seen in maximum number of cases $(35.9 \%)$ and range $12-13 \%$ in minimum number of cases (1.3\%). (Table: 2$)$

A statistically significant $(\mathrm{p}=<0.05)$ correlation was observed between anaemia and placental thickness. Anaemic patient were seen with increased placental thickness as compared with nonanaemic patient.

Table 2: Distribution of hemoglobin concentration

\begin{tabular}{|l|c|c|c|}
\hline Hemoglobin \% & IUGR & Normal & Total \\
\hline $4-5$ & 10 & 0 & 10 \\
\hline $5-6$ & 8 & 1 & 9 \\
\hline $6-7$ & 14 & 5 & 19 \\
\hline $7-8$ & 33 & 39 & 72 \\
\hline $8-9$ & 42 & 78 & 120 \\
\hline $9-10$ & 29 & 131 & 160 \\
\hline $10-11$ & 6 & 30 & 36 \\
\hline $11-12$ & 3 & 10 & 13 \\
\hline $12-13$ & 2 & 4 & 6 \\
\hline Total no. of cases & 147 & 298 & 445 \\
\hline
\end{tabular}

\section{Discussion}

From previous studies it has been seen that placental size increases linearly with advancing gestational age. Any abnormal thin or thick placenta may be an indicator of abnormal fetal outcome or any pathological condition. Elsafi Ahmed Abdalla Balla et al $^{[4]}$ reported that placental thickness less than $25 \mathrm{~mm}$ in third trimester is subnormal and may be associated with intrauterine growth retardation and placental thickness more than 40 in third trimester is abnormally thick and may represent pathological condition like maternal diabetes mellitus, fetal hydrops, intra uterine infections.

In the present study we found a linear relation between placental thickness and gestational age by LMP in both normal and IUGR cases from $18^{\text {th }}$ week to $40^{\text {th }}$ week. In normal cases placental thickness in $\mathrm{mm}$ is almost corresponding with gestational age (LMP) in weeks from 18 to 32 week after that placental thickness is slightly decreased and remains nearly constant with average placental thickness $31 \mathrm{~mm}$ till $40^{\text {th }}$ week. Maximum mean placental thickness in normal group was $33 \mathrm{~mm}$ at 36 week.

Hoddick et $\mathbf{a l}^{[5]}$ found average placental thickness (in $\mathrm{mm}$ ) to be roughly equivalent to gestational age (in weeks). Mital $\mathbf{P}$ and Hooja $\mathbf{N}^{[6]}$ also found an increasing trend in the values of mean placental thickness (in $\mathrm{mm}$ ) with increase in gestational age (in weeks) and the placental thickness (in $\mathrm{mm}$ ) coincides almost exactly with the gestational age in weeks. Anupama Jain et al ${ }^{[7]}$ reported similar correlations between placental thickness and gestational age. They found placental thickness (in $\mathrm{mm}$ ) almost matched gestational age (in weeks) from 27 weeks to 33 weeks of gestation. Grannum et $\mathbf{a l}^{[\mathbf{8 0}}$ reported that placental thickness would increase linearly until 33 weeks of pregnancy, after which there was gradual thinning.Other authors reported similar findings. Berkowitz et al $^{[9]}$ reported gradual decrease in placental size after 32 weeks until term.

In IUGR group also a linear relation is seen between placental thickness and gestational age by LMP. But like normal group value of placental thickness in $\mathrm{mm}$ does not coincides with gestational age in weeks except in 21, 28 and 34 gestational weeks. More diverse value of placental thickness is seen in IUGR cases (large standard deviation) as compared to normal cases. It suggest that thin or thick both type of placenta are associated with intrauterine growth retardation. Statistical significant difference in the mean placental thickness of normal and IUGR group is seen only in $18^{\text {th }}, 19^{\text {th }}$ and $26^{\text {th }}$ gestational weeks by LMP, with mean values more in IUGR $(22.5 \pm 4.2$, $28.1 \pm 5.2$ and $31 \pm 5.5)$ and less in normal cases $(18.7 \pm 1.6, \quad 19.6 \pm 1.9$ and $26 \pm 3.1)$. So earliest identification of IUGR pregnancy is possible by USG in these gestational weeks.

Cross sectional prospective study of correlation between placental thickness and gestational age is done in both normal and IUGR group by Mathai et $\mathbf{~ a l}^{[10]}$ (2013) in India. They also found positive correlation between placental thickness and ultrasonographic gestational age in both normal and IUGR groups. In their study statistically significant difference in the mean placental thickness in both groups was seen in $26^{\text {th }}$ and $30^{\text {th }}$ ultrasonographic gestational weeks with mean 
placental thickness lower in IUGR group as compared to normal group.

Placental thickness changes are an expression of normal growth of the fetoplacental unit amenable to measurement with USG and of value in describing normal physiology. Some diseases or abnormalities of the fetus can be detected through measurement of placental thickness. The measurements relative to gestational age should serve to facilitate recognition of altered placental thickness induced by pathologic processes.

Thin placenta is often a marker for a small for dates fetus and a sign of growth restriction. Placental thinning is also seen in patients with pre-eclampsia, chromosomal abnormalities and severe intra-uterine infection.

Thick placentas are associated with hydrops fetalis, diabetes mellitus, anemia and intrauterine infections. Sonographically thick placenta is associated with increased perinatal risk and increased mortality related to fetal anomalies and higher rates of both small for gestational age and large for gestational age infants at term.

\section{Conclusion}

- Placental thickness at the umbilical cord insertion site can be used as an accurate sonographic parameter in the assessment of gestational age in singleton normal pregnancies because of its strong positive linear correlation with gestational age.

- Value of placental thickness in $\mathrm{mm}$ coincides with gestational age in weeks from 18 to 32 gestational week by LMP. After 32 weeks placental thickness slightly reduces and remains nearly constant with average thickness $31 \mathrm{~mm}$ till 40 week.

- An abnormally thick or thin placenta is associated with IUGR pregnancies. Pregnancies with placenta thickness below or above the normal range of placental thickness in particular gestational week should facilitate detection of IUGR and other pathological conditions like hydrops fetalis, maternal diabtes mellitus, severe anaemia.

- By ultrasonography IUGR cases with increased placental thickness can be detected as early as $18^{\text {th }}$ gestational week in regions with increased prevalence of anaemia.

\section{References}

1. Donald I. On launching a new diagnostic science. Am J Obstet Gynecol 1968; 103:609-28.

2. Mital P, Hooja N, Mehndiratta K. Placental thickness - A sonographic parameter for estimating gestational age of the fetus. Ind J RadiolImag2002;12:553-4.

3. Jain A, Kumar G, Agarwal U, Kharakwal S. Placental thickness - A sonographic indicator of gestational age. J Obstet Gynaecol India 2001;51:48-9.

4. Elsafi AA, Magdolein SA, Caroline EA, Abdelmoneim SA. Prediction of fetal growth by measuring the placental thickness using Ultrasonography. Journal of Gynecology and Obstetrics. 2014; 2(2): 26-31.

5. Hoddick WK, Mahoney BS, Callen FW, Filly RA. Placental thickness. J Ultrasound Med. 1985; 4: 479-482.

6. Mital P, Hooja N, Mehndiratta. Placental thickness - a sonographic parameter for estimating gestational age of the fetus. Ind J RadiolImag. 2002; 12( 4): 553-554.

7. Anupama Jain, Ganesh Kumar, Agarwal U, Kharakwal S. Placental thickness - a sonographic indicator of gestational age. Journal of obstetrics and gynaecology of India. 2001; 51(3): 48-49.

8. Granum PAT, Hobbins JC. The placenta. Radiol Clin North Am. 1982; 20: 353.

9. Granum PAT, Berkowitz RL, Hobbins JC. The ultrasonic changes in the maturing placenta and their relation to fetal pulmonic maturity. Am J Obstet Gynecol. 1979; 133: 915-922. 
10. Mathai B M , Singla S C , Nittala P P, Chakravarti R J, Toppo J N. Placental thickness: its correlation with ultrasonographic gestational age in normal and intrauterine growth-retarded pregnancies in the late second and third trimester. The Journal of Obstetrics and Gynecology of India.2013; 63(4):230-233. 